\title{
Long term efficacy and toxicity after stereotactic ablative reirradiation in locally relapsed stage III non-small cell lung cancer
}

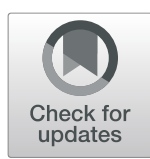

Shakeel Sumodhee ${ }^{1,2^{*}}$, Pierre-Yves Bondiau ${ }^{1,2}$, Michel Poudenx ${ }^{2,3}$, Charlotte Cohen ${ }^{2,4}$, Arash O. Naghavi ${ }^{5}$, Bernard Padovani ${ }^{2,6}$, Daniel Maneval ${ }^{1,2}$, Jocelyn Gal ${ }^{2,7}$, Axel Leysalle ${ }^{1,2}$, Hannah Ghalloussi ${ }^{2,3}$, Josiane Otto ${ }^{2,3}$ and Jérôme Doyen ${ }^{1,2}$

\begin{abstract}
Background: In stage III non-small cell lung cancer (NSCLC) treated with concomitant chemoradiotherapy, there is a high rate of relapse. Some of these relapses are only local and can be treated by stereotactic ablative radiation therapy (SABR). Previous studies reporting outcome after SABR reirradiation of the thorax consisted of a heterogeneous population of various lung cancer stages or even different types of cancer. The purpose of study is to evaluate toxicity and outcome of this strategy in locally relapsed stage III NSCLC only.

Methods: From February 2007 to November 2015, 46 Stage III NSCLC patients treated with SABR, for lung recurrence following conventionally fractionated radiation therapy (CFRT), were retrospectively analyzed.

Results: Median follow-up was 47.3 months (1-76.9). The 2 and 4-year progression-free survival (PFS), and overall survival (OS) were of $25.5 \% / 8.6$ and $48.9 \% / 30.8 \%$, respectively. Highest presenting toxicity in patients (grade 1 through 5) was: 13 (28.3\%), 7 (15.2\%), 1 (2.2\%), 0 and $2(4.4 \%)$, with deaths due to hemoptysis $(n=1)$ and alveolitis $(n=1)$. Although the Biological Effective Dose (at Planning Tumor Volume isocenter) was lower for central tumors treated for an in-field relapse $(n=21,116 \mathrm{~Gy}$ versus $168 \mathrm{~Gy}, p=0.005)$, they had no significant difference in OS than the remaining cohort, but with a higher rate of grade $2-5$ toxicities ( $\mathrm{OR}=0.22,[0.06-0.8], p=0.02)$.

Conclusion: Reirradiation with SABR for local relapse in patients previously treated for stage III NSCLC, is feasible and associated with good outcome. This is also true for central tumors treated for an in-field relapse, but should be radiated with caution to mitigate toxicity.
\end{abstract}

Keywords: Stage III non-small cell lung cancer, Stereotactic radiotherapy, Reirradiation, Toxicity, Efficacy

\section{Background}

Conventionally fractionated radiation therapy (CFRT) with concurrent chemotherapy is the standard of care in patients who have been diagnosed with stage III non-small cell lung cancer (NSCLC) [1], and approximately $40 \%$ of these patients will experience intrathoracic recurrences [2]. In this situation, patients may get second-line chemotherapy, salvage surgery, or reirradiation with either CFRT or stereotactic ablative

\footnotetext{
* Correspondence: shakeel.sumodhee@nice.unicancer.fr

'Department of Radiation Oncology, Centre Antoine-Lacassagne, 33 av de Valombrose, 06189 Nice, France

University of Côte d'Azur, Nice, France

Full list of author information is available at the end of the article
}

radiotherapy (SABR). The best treatment strategy for intrathoracic recurrences remains unclear, but local treatment is the first choice whenever possible. Previous experience with lung reirradiation with CFRT yields suboptimal 2-years overall survival (OS) of $5-27 \%$ with a $5-20 \%$ risk of grade $\geq 3$ toxicity [3]. SABR is highly effective in the treatment of inoperable stage I lung cancer and has become the standard of care for this group of patients [1]. The effectiveness of SABR arises from the high biologically effective dose (BED) it can achieve in the tumor while maintaining a sharp dose gradient fall off outside the target, preventing dose to critical structures. Higher BED has been associated with improved OS and local tumor control rates in NSCLC $[4,5]$.

(c) The Author(s). 2019 Open Access This article is distributed under the terms of the Creative Commons Attribution 4.0 International License (http://creativecommons.org/licenses/by/4.0/), which permits unrestricted use, distribution, and 
Better dose delivery leads to smaller treatment field and steeper dose drop to organs at risk, which is particularly important in the case of re-irradiation, and can mitigate treatment related sequela. Several studies already reported an acceptable toxicity profile with SABR thoracic reirradiation with 0 to $30 \%$ late grade $3-5$ pneumonitis, with rare observations of late esophagitis, skin ulceration or fatal hemoptysis [6-15]. In these studies, it is difficult to evaluate outcome because of their short follow-up and patient heterogeneity (previous stage I, II, III or oligometastatic IV disease) [12].

The purpose of the present study is to retrospectively assess toxicity and outcomes of thoracic reirradiation with SABR in patients with locally recurrent NSCLC who were previously treated with CFRT and concurrent chemotherapy limited to stage III NSCLC patients.

\section{Methods}

\section{Patient selection}

With institutional review board approval, we retrospectively reviewed all patients receiving thoracic reirradiation at our institution. We identified all patients with prior history of CFRT for stage III NSCLC, who underwent SABR for local relapse from $02 / 2007$ to $11 / 2015$. All patients were discussed at tumor board and SABR was chosen because patients were not deemed medically operable and because radiofrequency is not considered in previously irradiated patients at our center for safety concerns. Local relapse was determined according to Response Evaluation Criteria in Solid Tumors (RECIST) version 1.1. which is based on imaging findings (CT-scan) [16]. For controversial cases between lung alveolitis and tumor recurrence, we used 18-FDG positron emission tomography-computed tomography and biopsy through lung fibroscopy or CT-scan.

In order to be considered as local recurrence/reirradiation situation, the mass had to be located in the ipsilateral lung and/or in the mediastinum [17] (because previous irradiation was performed with 3 dimensional conformal radiation therapy (3D-CRT) for stage III disease, relapses consequently occurred at least the low/ intermediate dose level).

Tumors were considered "central" if they were located $<2 \mathrm{~cm}$ from the central airways in any direction (trachea, carina and main bronchus up to the division of the second order bronchi), as per the Radiation Therapy Oncology Group protocol 0813 definition [18].

\section{Treatment}

The treatment protocol for SABR has been previously described in detail [19]. Patients were immobilized with a personalized vacuum cushion. The Cyberknife ${ }^{\circ}$ (Accuray, Sunnyvale, United States of America) technology was used for the stereotactic treatment. It is characterized by an image-guided, real-time repositioning of the treatment beam during the irradiation session, which is possible after the implantation of gold fiducials into the tumor. Non-coplanar pencil beams using $6 \mathrm{MV}$ photons with ray-tracing dosimetric calculation for delivered dose were utilized for all treatments. Dose constraints reported by the AAPM Task Group 101 were used for SABR treatment [20]. There was no dose constraints adaptation regarding the previous received dose, but the following precautions were performed: (i) patients could be treated only if there was a minimal of 6 months delay from their last irradiation; (ii) a GTV / CTV margin and a CTV / PTV margin of 0 $\mathrm{mm}$ and $1-2 \mathrm{~mm}$ were used, (http://www.cyberknifela tin.com/pdf/brochure-tecnico.pdf), respectively; (iii) the dose was prescribed to the $75-85 \%$ isodose line in order to cover the entire PTV volume with $95 \%$ of the prescribed dose, and fitted the ICRU-Report 91 for stereotactic radiotherapy; the dose per fraction was decreased if the tumor was centrally located (5 fractions of 10-12 Gy every 2 days instead of 3 consecutive fractions of 20 Gy); (iv) organ at risk protection had to be prioritized over target coverage.

\section{Follow-up}

Patients underwent computed tomographic scan of the thorax and/or positron emission tomography-computed tomography within 7-9 weeks of treatment completion and every 3-6 months thereafter. Tumor response was evaluated according to RECIST 1.1 criteria [16]. Time-to-event outcomes were defined from the last day of SABR. Local control (LC) and locoregional control (LRC) were defined from the last day of SABR to day of local relapse within the irradiated site for LC, and to day of local and/or regional (homolateral thoracic) relapse for LRC. Metastasis-free survival (MFS) was defined as the time to relapse outside the irradiated field. Progression-free survival (PFS) was determined by the time to any relapse (locoregional or metastasis). Overall survival (OS) was defined by the time to death from any cause.

Prior to treatment with SABR, NSCLC patients with a local failure were defined as recurrence after evidence of increased size of enhancing tumor in the treated region. If there were difficulties to assess progression, biopsy through lung fibroscopy was performed. Toxicities were evaluated according to Common Terminology Criteria for Adverse Event (CTCAE) version 4.0. We attempt to contact patients, family or general practitioners in order to collect toxicity and survival data. We could not contact patients who died because of cancer but close medical follow-up was available for them $(n=19)$, and we succeeded in contacting 20 patients $(7(15.2 \%)$ patients could not be reached). In this cohort, in-field relapse 
prior to SABR, was defined as a relapse within the previously irradiated PTV.

\section{BED calculation}

BED was calculated with the following formula: $B E D=n$ $\mathrm{x} \mathrm{d}[1+(\mathrm{d} / \alpha / \beta)]$, where $\mathrm{n}=$ number of fractions, $\mathrm{d}=$ dose per fraction and $\alpha / \beta=10$ for non-small lung cancer. BED was evaluated at the Planning Tumor Volume (PTV) isocenter. The minimum BED for the encompassing dose was also reported.

\section{Statistical analysis}

Qualitative data are represented as frequency, percentage and confidence interval 95\%. Statistical comparisons were performed using Chi-square tests for categorical data and Mann-U-Whitney's test for continuous variables. For analysis of quantitative variables, cut-offs were based on the variable's median value. LC, LRC, MFS, PFS and OS were estimated and presented graphically using the Kaplan Meier method. Patients were censored at the time of death or last follow-up. Survival rates at various times and 95\% confidence intervals were also estimated. Log-rank analysis was performed in order to identify potential factors correlated with survival.

All statistical analyses were performed in 5\% alpha risk or 95\% confidence interval using Statistical Package for the Social Sciences (SPSS) version 16.0 on Windows ${ }^{\oplus}$. Since premature death may lead to underreporting LC and LRC, competing risk regression model was used to describe LC and LRC survival while considering death as a competing event. Competing risk regression model was also used to determine factors correlated with LC or LRC survival. Subhazard Ratio and 95\% confidence intervals were provided for competing risk regression. Stata version 15.1 software was used for these analyses.

\section{Results}

\section{Characteristics of patients, treatments and lesions} (Table 1)

A total of 46 patients were reirradiated with SABR. Twenty-nine (63\%) patients were referred by other centers in our country for the treatment of their local relapse. The characteristics of both patients and lesions are shown in Table 1. All patients were treated for a single tumor volume. Tumor board recommended systemic chemotherapy after SABR for 10 patients (Table 1). A second relapse was treated with a second course of SABR for 2 patients while all other relapsed patients were treated with systemic treatment. Seven patients got less than 60 Gy during previous irradiation but were still treated with curative intent because eventually underwent surgery after chemoradiotherapy, due to very good response [21].
Median size of reirradiated tumors was $33 \mathrm{~mm}$ (10-60). The median time from primary CFRT treatment to reirradiation with SABR was 22.6 months (6.2-101.5). Type of concomitant chemotherapy is reported in Table 1.

\section{Response and survival data (Table 2, Figs. 1 and 2)}

There were 10 (21.7\%) complete responses (CR), 19 (41.3\%) partial responses (PR), 14 (30.4\%) stabilized disease (SD) and $3(6.5 \%)$ immediate local progressive disease (PD). Improvement in the $C R$ and $P R$ rate was associated with tumor size $<33 \mathrm{~mm}$, patients treated for an out-of-field relapse, and PTV coverage $\geq 90 \%$. On multivariate analysis, only tumor size independently predicted for tumor response (Table 2).

With a median follow up of 47.3 months (1-76.9), 34 patients experienced a relapse (16 local relapse, 13 regional relapse, 21 metastatic relapse), and 29 patients died. The Kaplan-Meier estimated 4-year LC and LRC rate were 44.2 and $14.7 \%$, respectively. Competing risk analysis identified a 4-year rate of local relapse and locoregional relapse of respectively 40 and 67\% (Fig. 2). The 4-year PFS, MFS and OS rate were 10.8, 30.8 and $30.8 \%$, respectively (Fig. 1 ). The median LC, LRC, MFS, PFS and OS were 36.3 months (2.2-68.2), 13.8 months (1;76.9), 28.3 months (1-76.9), $9.6(1-62.5)$ and 21.8 months (2.6-76.9), respectively (Kaplan Meier). Of note, the cause of death was either not related to cancer or unknown in 9 of 29 patients. Among these 9 patients, there were two treatment related death, 3 lethal documented lung infection, and 4 deaths from unknown cause. For these 4 patients there was no relapse at last follow-up.

\section{Predictive factors for LC, LRC, MFS, PFS and OS (Tables 3 and 4)}

On univariate analysis, the location of relapse was associated with worse local control, specifically disease in the central thorax (SHR: 3.2 [1.1;9.5], Fig. 2c).

Of note, the BED (at PTV isocenter) delivered to central tumors was lower than the BED delivered to peripheral tumors ( $116 \mathrm{~Gy}$ versus $180 \mathrm{~Gy}, p=0.004$ ), as well was the BED delivered to central tumors with an in-field relapse in comparison with others (113 Gy vs $150 \mathrm{~Gy}, p$ $=0.007$ ). Tumor size, Gross Tumor Volume (GTV) and PTV coverage did not differ between peripheral and central tumors ( $p=0.06, p=0.11, p=0.4$, respectively).

PTV coverage was the unique predictive factor for locoregional relapse rate (lower rate of locoregional relapse if coverage $\geq 90 \%$ : $\mathrm{SHR}=0.4[0.2 ; 0.98], p=0.04$, Fig. 2d).

No factors correlated with MFS. Male presented with improved PFS in univariate analysis (2-year PFS: $29.5 \%$ versus $11.3 \%, p=0.02$ ). 
Table 1 Patient Demographics and Treatment Characteristics

\begin{tabular}{|c|c|c|}
\hline Demographic or Clinical Characteristic & No. of patients & $\%$ \\
\hline Median age, years (range) & $66(44.3-83.3)$ & \\
\hline Median follow-up, months (range) & $47.3(1-76.9)$ & \\
\hline \multicolumn{3}{|l|}{ Gender } \\
\hline Male & 35 & 76. \\
\hline Female & 11 & 23. \\
\hline \multicolumn{3}{|l|}{ Histology } \\
\hline Squamous & 22 & 47. \\
\hline Non-squamous & 24 & 52. \\
\hline \multicolumn{3}{|l|}{ Performans Status - ECOG ${ }^{a}$} \\
\hline 0 & 27 & 71. \\
\hline 1 & 11 & 28. \\
\hline Missing & 8 & \\
\hline \multicolumn{3}{|l|}{ Location of relapse } \\
\hline Central & 24 & 52. \\
\hline Peripheral & 22 & 47. \\
\hline \multicolumn{3}{|l|}{ In-field relapse } \\
\hline Yes & 29 & 63 \\
\hline No & 17 & 37 \\
\hline
\end{tabular}

Primary stage (at first irradiation)

IIIA

$\| \mathrm{B}$

Concurrent chemotherapy at first irradiation

Yes

No

Surgery immediately after the first irradiation

Yes

No

First irradiation

Median total dose

Median dose per fraction

Total dose < 60 Gy

Median BED dose

Concomitant chemotherapy (first irradiation)

Cisplatin - Docetaxel

Carboplatin - Paclitaxel

Cisplatin - Navelbine

Carboplatin - Etoposide

Carboplatin - Docetaxel

Cisplatin - Paclitaxel

Cisplatin - Etoposide

Carboplatin - Gemcitabine

Carboplatin - Navelbine

Unknown
Table 1 Patient Demographics and Treatment Characteristics (Continued)

\begin{tabular}{|c|c|c|}
\hline Demographic or Clinical Characteristic & No. of patients & $\%$ \\
\hline \multicolumn{3}{|l|}{ Reirradiation } \\
\hline Median delay between irradiations & $22.6(6.2-101.5)$ & \\
\hline Median tumor size in mm & $33(10-60)$ & \\
\hline Median GTV in mL & $13.2 \mathrm{~mL}(1.1-79.1)$ & \\
\hline Median duration of treatment in days & $5(3-12)$ & \\
\hline Median total physical prescribed dose in Gy & $60(40-75)$ & \\
\hline Median prescribed dose per fraction in Gy & $16(10-20)$ & \\
\hline Median number of sessions & $4(3-5)$ & \\
\hline Median BEDisocenter in Gy & $132(72-187.5)$ & \\
\hline Median BED in Gy & $50.2(6.7-189.1)$ & \\
\hline Isodose of prescription in \% & $80(70-83)$ & \\
\hline Median GTV coverage in \% & $95.6(43.8-100)$ & \\
\hline Median PTV coverage in \% & $90.2(34.8-100)$ & \\
\hline \multicolumn{3}{|l|}{ Adjuvant chemotherapy after reirradiation } \\
\hline Yes $^{a}$ & 10 & 21.7 \\
\hline No & 36 & 78.3 \\
\hline
\end{tabular}

The only factor associated with OS was age (age $<66$ years was correlated with improved 2-year OS rate: $65.7 \%$ vs $31.3 \%, \mathrm{p}=0.02$ ). There was a trending 2 -year OS detriment associated with larger tumor size $\geq 33 \mathrm{~mm}$ (31.7\% vs $69.8 \%, p=0.059)$, interval to reirradiation $<12$ months $(12.7 \%$ vs $59.5 \%, p=0.07)$ and in-field relapse ( $40 \%$ vs $74.5 \%, p=0.06)$.

76.1

Toxicity profile (Table 5)

Side effects after SABR were reported by 24 (52.2\%) patients. Respiratory symptoms were observed in 12 patients $(26.1 \%)$ and one patient died from radiation alveolitis. Thirteen (28.3\%), 7 (15.2\%), 1 (2.2\%), 0 and 2 (4.4\%) patients presented with a maximum toxicity grade of 1, 2, 3, 4 and 5, respectively. One patient died because of hemoptysis and another, as already mentioned, from radiation alveolitis. Additional file 1: Table S1 describes characteristics of the 2 patients who experienced fatal toxicities. Of note, the patient with grade 5 hemoptysis presented with an elevated dose to the proximal bronchial vascular tree.

The 2 patients treated with 2 SABR reirradiations had no grade 3 or more toxicities. One patient presented with second primary breast cancer requiring hospitalization; this may be a radiation associated malignancy and was consequently classified as a grade 3 toxicity.

Predictive factors for grade 2-5 toxicities (Table 6)

On univariate analysis, predictive factors for a higher rate of grade $2-5$ toxicities were tumor size $\geq 33 \mathrm{~mm}$, 
Table 2 Predictive factors for tumor response

\begin{tabular}{|c|c|c|c|c|c|}
\hline Variable & Complete or Partial Response & Stabilization or progression & $p$ value (Chi Square) & Binary logistic regression ${ }^{b}$ & $p$-value \\
\hline \multicolumn{6}{|l|}{ Gender } \\
\hline Male $(n=35)$ & $60 \%$ & $40 \%$ & 0.4 & $\mathrm{Nl}$ & \\
\hline Female $(n=11)$ & $72.7 \%$ & $27.3 \%$ & & & \\
\hline \multicolumn{6}{|l|}{ Histology } \\
\hline Squamous $(n=22)$ & $59.1 \%$ & $40.9 \%$ & 0.6 & $\mathrm{NI}$ & \\
\hline Non squamous $(n=24)$ & $66.7 \%$ & $33.3 \%$ & & & \\
\hline \multicolumn{6}{|l|}{ Age } \\
\hline$<66$ years $(n=23)$ & $69.6 \%$ & $30.4 \%$ & 0.3 & $\mathrm{Nl}$ & \\
\hline$\geq 66$ years $(n=23)$ & $56.5 \%$ & $43.5 \%$ & & & \\
\hline \multicolumn{6}{|l|}{ Dose of reirradiation } \\
\hline BED $\leq 130$ Gy $(n=18)$ & $50 \%$ & $50 \%$ & 0.14 & $\mathrm{Nl}$ & \\
\hline BED > 130 Gy $(n=28)$ & $71.4 \%$ & $28.6 \%$ & & & \\
\hline BEDmin $\leq 50$ Gy $(n=22)$ & $54.5 \%$ & $45.5 \%$ & 0.3 & $\mathrm{Nl}$ & \\
\hline BEDmin > 50 Gy $(n=23)$ & $69.6 \%$ & $30.4 \%$ & & & \\
\hline \multicolumn{6}{|l|}{ Tumor size } \\
\hline$\geq 33 \mathrm{~mm}(n=21)$ & $42.9 \%$ & $57.1 \%$ & 0.008 & 1 & 0.04 \\
\hline$<33 \mathrm{~mm}(n=22)$ & $81.8 \%$ & $18.2 \%$ & & $\mathrm{OR}=0.21$ & \\
\hline Missing value $(n=3)$ & & & & {$[0.04-0.93]$} & \\
\hline \multicolumn{6}{|l|}{ GTV Volume } \\
\hline$\geq 13 \mathrm{~mL}(n=22)$ & $33.3 \%$ & $76.5 \%$ & 0.005 & $\mathrm{NI}$ & \\
\hline$<13 \mathrm{~mL}(n=22)$ & $66.7 \%$ & $23.5 \%$ & & & \\
\hline \multicolumn{6}{|l|}{ Missing value $(n=2)$} \\
\hline \multicolumn{6}{|l|}{ SABR duration } \\
\hline$\geq 6$ days $(n=25)$ & $64 \%$ & $36 \%$ & 0.8 & $\mathrm{NI}$ & \\
\hline$<6$ days $(n=21)$ & $61.9 \%$ & $38.1 \%$ & & & \\
\hline \multicolumn{6}{|l|}{ Number of fractions } \\
\hline$>3(n=30)$ & $60 \%$ & $40 \%$ & 0.5 & $\mathrm{Nl}$ & \\
\hline$\leq 3(n=16)$ & $68.8 \%$ & $31.2 \%$ & & & \\
\hline \multicolumn{6}{|l|}{ Dose per fraction } \\
\hline$>12(n=23)$ & $69.6 \%$ & $30.4 \%$ & 0.3 & $\mathrm{NI}$ & \\
\hline$\leq 12(n=16)$ & $56.5 \%$ & $43.5 \%$ & & & \\
\hline \multicolumn{6}{|l|}{ Performans Status ECOG ${ }^{a}$} \\
\hline $0(n=27)$ & $70.4 \%$ & $29.6 \%$ & 0.9 & $\mathrm{Nl}$ & \\
\hline $1(n=11)$ & $72.7 \%$ & $27.3 \%$ & & & \\
\hline \multicolumn{6}{|l|}{ Missing value $(n=8)$} \\
\hline \multicolumn{6}{|l|}{ Location of relapse } \\
\hline Central $(n=24)$ & $50 \%$ & $50 \%$ & 0.06 & $\mathrm{Nl}$ & \\
\hline Peripheral $(n=22)$ & $77.3 \%$ & $22.7 \%$ & & & \\
\hline \multicolumn{6}{|c|}{ Primary stage (at first irradiation) } \\
\hline$\| I I A(n=21)$ & $61.9 \%$ & $38.1 \%$ & 0.9 & $\mathrm{Nl}$ & \\
\hline IIIB $(n=25)$ & $64 \%$ & $36 \%$ & & & \\
\hline \multicolumn{6}{|l|}{ In-field relapse } \\
\hline Yes $(n=29)$ & $48.3 \%$ & $51.7 \%$ & 0.03 & 1 & 0.14 \\
\hline No $(n=17)$ & $82.4 \%$ & $17.6 \%$ & & $\mathrm{OR}=0.26[0.04-1.6]$ & \\
\hline
\end{tabular}


Table 2 Predictive factors for tumor response (Continued)

\begin{tabular}{|c|c|c|c|c|c|}
\hline Variable & Complete or Partial Response & Stabilization or progression & $p$ value (Chi Square) & Binary logistic regression ${ }^{b}$ & $p$-value \\
\hline \multicolumn{6}{|c|}{ In-field relapse and central tumors } \\
\hline Yes $(n=19)$ & $35.3 \%$ & $64.7 \%$ & 0.01 & $\mathrm{Nl}^{\mathrm{c}}$ & \\
\hline No $(n=26)$ & $72.4 \%$ & $27.6 \%$ & & & \\
\hline \multicolumn{6}{|l|}{ GTV coverage } \\
\hline$<95 \%(n=22)$ & $50 \%$ & $50 \%$ & 0.07 & $\mathrm{NI}$ & \\
\hline$\geq 95 \%(n=24)$ & $75 \%$ & $25 \%$ & & & \\
\hline \multicolumn{6}{|l|}{ PTV coverage } \\
\hline$<90 \%(n=23)$ & $47.8 \%$ & $52.2 \%$ & $p=0.03$ & 1 & 0.11 \\
\hline$\geq 90 \%(n=23)$ & $78.3 \%$ & $21.7 \%$ & & $\mathrm{OR}=3.2[0.74-13.8]$ & \\
\hline
\end{tabular}

${ }^{a}$ At time of stereotactic ablative radiotherapy; ECOG = Eastern Cooperative Oncology Group

${ }^{\mathrm{b}}$ Complete-Partial response versus stabilization-progression

"If "in-field relapse and central tumors" is included in multivariate model instead of "in-field relapse": $p$-value for "in-field relapse and central tumors" $=0.08$ ( 0.03 for tumor size and 0.15 for PTV coverage)

central tumors and in-field relapse. Central tumors and in-field relapse had a higher rate of grade $2-5$ toxicities. Initial multivariate analysis showed no factors associated with toxicity. Replacing the location of relapse (central vs. peripheral) and whether the tumor was an in-field relapse at the time of SABR with a variable incorporating both risks (in-field relapse and central vs. other), was independently predictive of grade $2-5$ toxicity on multivariate analysis.

\section{Discussion}

This study reports the outcome of patients previously treated with CFRT for stage III NSCLC, and reirradiated with SABR because of lung recurrence.
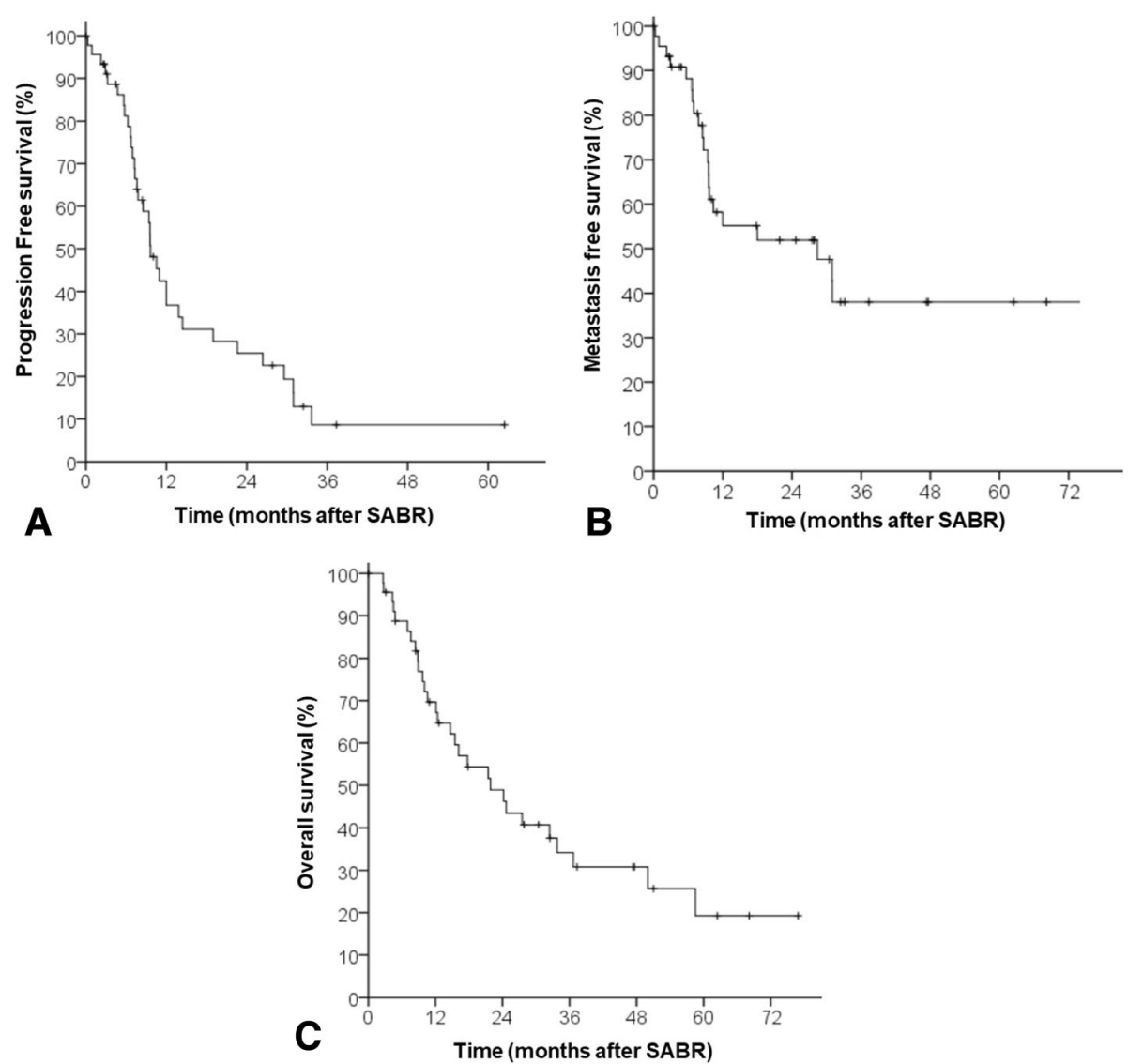

Fig. 1 Progression-Free Survival (a), Metastasis-Free Survival (b), and Overall Survival (c) 


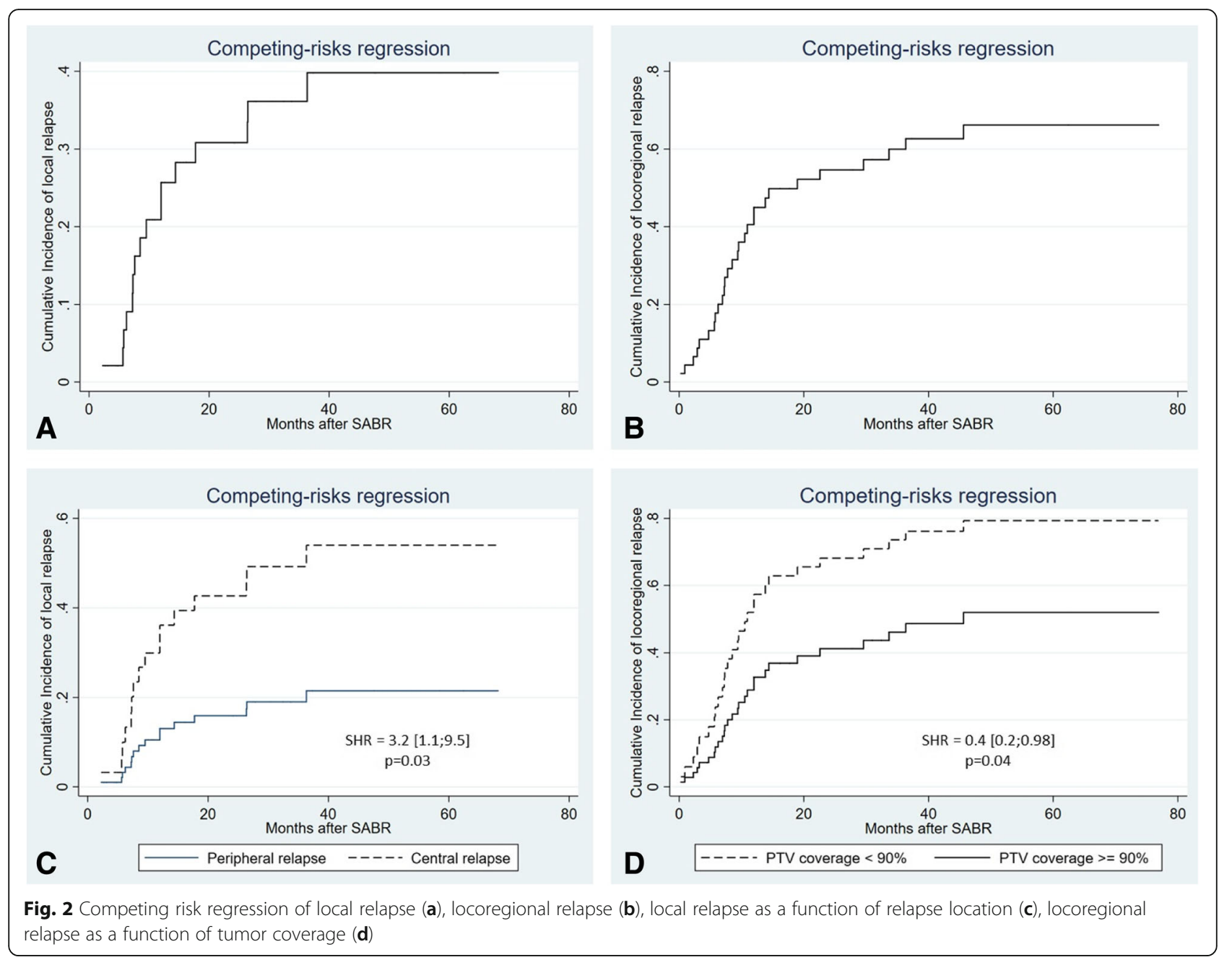

At last follow-up, 32 patients had relapsed (16 local, 13 regional and 21 metastatic relapse), and 29 patients died, leading to a 2 and 4-year PFS and OS of 26.1\%/ 10.8 and $48.9 \% / 30.8 \%$, respectively (Kaplan-Meier). Thus, approximately one-third of patients were alive 4 years after SABR but only $10.8 \%$ free of relapse, emphasizing that in addition to local control, distant control is concerning for this population. Although adjuvant chemotherapy was not prognostic in the present study (Tables 3 and 4), it was likely underpowered to address this question. The latest National Comprehensive Cancer Network guidelines (NCCN version 3.2019) regarding local recurrence in NSCLC advises reresection or SABR with no clear recommendation on the treatment thereafter (observation or systemic therapy). To our knowledge, there is no study which analysed the impact of adjuvant chemotherapy after the treatment of local recurrence in stage III NSCLC. However, regarding the high rate of relapse following SABR reirradiation, adjuvant systemic treatment (chemotherapy, immunotherapy) may be recommended. Newer strategies could combine SABR and immunotherapy, as the SABR may improve immunotherapy efficacy, as described in the recent randomized phase II trial for advanced NSCLC [22].

In our study, age was the only variable associated with OS. Otherwise, there were no factors significantly correlated with MFS, PFS or OS, and interestingly central tumors treated with SABR for an in-field relapse had no significant difference in OS, when compared to the remaining cohort. In this subgroup there was also a significant increase of grade $2-5$ toxicities $(42.9 \%$ versus $4.5 \%, p=0.007$ ). This consequently suggests that patients with central and in-field relapse are also good candidate for SABR reirradiation. Of note central tumors $(n=24)$ presented with a higher risk of local relapse suggesting that the absence of LC difference between central tumors treated for an in-field relapse $(n=21)$ with others, may be due to a lack of statistical power.

In the present cohort the cause of death was not only cancer related but also to treatment related toxicities $(n=2)$, lung infection $(n=3)$ and unknown cause $(n=4)$. A recent study found that cause of 
Table 3 Prognostic factors for local control (LC), Locoregional control (LRC) and metastasis-free survival (MFS)

\begin{tabular}{|c|c|c|c|c|}
\hline \multirow[b]{2}{*}{ Variable } & \multicolumn{2}{|l|}{$\underline{\text { Local relapse }}$} & \multicolumn{2}{|l|}{$\underline{\text { Locoregional relapse }}$} \\
\hline & Subhazard Ratio (SHR, 95\% Cl) & $p$-value & Subhazard Ratio (SHR, 95\% CI) & $p$-value \\
\hline \multicolumn{5}{|l|}{ Gender } \\
\hline Male $(n=35)$ & 1 & $p=0.2$ & 1 & $p=0.5$ \\
\hline Female $(n=11)$ & $0.5[0.1-1.6]$ & & $0.7[0.3-1.9]$ & \\
\hline \multicolumn{5}{|l|}{ Histology } \\
\hline Non squamous $(n=24)$ & 1 & $p=0.3$ & 1 & $p=0.9$ \\
\hline Squamous $(n=22)$ & $1.48[0.6-3.2]$ & & $0.9[0.5-1.7]$ & \\
\hline \multicolumn{5}{|l|}{ Age } \\
\hline$<66$ years $(n=23)$ & 1 & $p=0.4$ & 1 & $p=0.9$ \\
\hline$\geq 66$ years $(n=23)$ & $1.4[0.5-3.7]$ & & $0.9[0.5-2]$ & \\
\hline \multicolumn{5}{|l|}{ Period between irradiations } \\
\hline$>24$ months $(n=20)$ & 1 & $p=0.8$ & 1 & $p=0.1$ \\
\hline$\leq 24$ months $(n=25)$ & $1.1[0.4-2.9]$ & & $1.8[0.8-3.9]$ & \\
\hline \multicolumn{5}{|l|}{ Missing value $(n=1)$} \\
\hline$>12$ months $(n=36)$ & 1 & $p=0.8$ & 1 & $p=0.5$ \\
\hline$\leq 12$ months $(n=9)$ & $1.09[0.3-3.6]$ & & $1.3[0.5-3.5]$ & \\
\hline \multicolumn{5}{|l|}{ Missing value $(n=1)$} \\
\hline \multicolumn{5}{|l|}{ Dose of reirradiation } \\
\hline BED > 130 Gy $(n=28)$ & 1 & $p=0.9$ & 1 & $p=0.09$ \\
\hline BED $\leq 130$ Gy $(n=18)$ & $0.9[0.3-2.5]$ & & $1.8[0.9-3.9]$ & \\
\hline BEDmin $\leq 50$ Gy $(n=22)$ & 1 & $p=0.16$ & 1 & $p=0.06$ \\
\hline BEDmin $>50$ Gy $(n=23)$ & $0.5[0.2-1.3]$ & & $0.5[0.2-1.05]$ & \\
\hline \multicolumn{5}{|l|}{ SABR duration } \\
\hline$\geq 6$ days $(n=25)$ & 1 & $p=0.4$ & 1 & $p=0.7$ \\
\hline$<6$ days $(n=20)$ & $1.5[0.56-4.11]$ & & $0.9[0.4-1.8]$ & \\
\hline \multicolumn{5}{|c|}{ Chemotherapy after reirradiation } \\
\hline Yes $(n=10)$ & 1 & & 1 & \\
\hline No $(n=36)$ & $1.6[0.4-5.5]$ & $p=0.4$ & $1.6[0.7-3.9]$ & $p=0.2$ \\
\hline \multicolumn{5}{|l|}{ Tumor size } \\
\hline$<33 \mathrm{~mm}(n=22)$ & 1 & & 1 & \\
\hline$\geq 33 \mathrm{~mm}(n=21)$ & $1.58[0.6-4.1]$ & $p=0.3$ & $1.6[0.8-3.5]$ & $p=0.18$ \\
\hline \multicolumn{5}{|l|}{ Missing value $(n=3)$} \\
\hline \multicolumn{5}{|l|}{ GTV Volume } \\
\hline$<13 \mathrm{~mL}(n=22)$ & 1 & & 1 & \\
\hline$\geq 13 \mathrm{~mL}(n=22)$ & $1.49[0.57-3.95]$ & $p=0.4$ & $1.83[0.87-3.82]$ & $p=0.10$ \\
\hline \multicolumn{5}{|l|}{ Missing value $(n=2)$} \\
\hline \multicolumn{5}{|l|}{ SABR duration } \\
\hline$\geq 6$ days $(n=25)$ & 1 & $p=0.4$ & 1 & $p=0.7$ \\
\hline$<6$ days $(n=21)$ & $1.51[0.56-4.1]$ & & $0.87[0.42-1.79]$ & \\
\hline \multicolumn{5}{|l|}{ Number of fractions } \\
\hline$\leq 3(n=16)$ & 1 & $p=0.09$ & 1 & $p=0.9$ \\
\hline$>3(n=30)$ & $2.85[0.85-9.6]$ & & $0.99[0.47-2.1]$ & \\
\hline \multicolumn{5}{|l|}{ Dose per fraction } \\
\hline$>12(n=23)$ & 1 & $p=0.8$ & 1 & $p=0.2$ \\
\hline$\leq 12(n=22)$ & $0.93[0.35-2.44]$ & & $1.54[0.74-3.21]$ & \\
\hline
\end{tabular}


Table 3 Prognostic factors for local control (LC), Locoregional control (LRC) and metastasis-free survival (MFS) (Continued)

\begin{tabular}{|c|c|c|c|c|}
\hline \multirow[b]{2}{*}{ Variable } & \multicolumn{2}{|l|}{$\underline{\text { Local relapse }}$} & \multicolumn{2}{|l|}{$\underline{\text { Locoregional relapse }}$} \\
\hline & Subhazard Ratio (SHR, 95\% Cl) & $p$-value & Subhazard Ratio (SHR, 95\% CI) & $p$-value \\
\hline \multicolumn{5}{|l|}{ Performans Status - ECOG ${ }^{a}$} \\
\hline $1(n=11)$ & 1 & $p=0.7$ & 1 & $p=0.19$ \\
\hline $0(n=27)$ & $0.78[0.2-2.9]$ & & $1.8[0.7-4.4]$ & \\
\hline \multicolumn{5}{|l|}{ Missing value $(n=8)$} \\
\hline \multicolumn{5}{|l|}{ Location of relapse } \\
\hline Peripheral $(n=22)$ Central & 1 & $p=0.03$ & 1 & $p=0.9$ \\
\hline$(n=24)$ & $3.2[1.1-9.5]$ & & $0.9[0.4-2.1]$ & \\
\hline \multicolumn{5}{|c|}{ Primary stage (at first irradiation) } \\
\hline$\| I I A(n=21)$ & 1 & $p=0.6$ & 1 & $p=0.11$ \\
\hline IIIB $(n=25)$ & $1.2[0.5-3.2]$ & & $1.8[0.9-3.7]$ & \\
\hline \multicolumn{5}{|l|}{ In-field relapse } \\
\hline No $(n=17)$ & 1 & $p=0.2$ & 1 & $p=0.2$ \\
\hline Yes $(n=29)$ & $2[0.7-5.9]$ & & $1.6[0.7-3.6]$ & \\
\hline \multicolumn{5}{|c|}{ In-field relapse and central tumors } \\
\hline No $(n=26)$ & 1 & $p=0.04$ & 1 & $p=0.8$ \\
\hline Yes $(n=19)$ & $2.8[1.1-7.3]$ & & $0.9[0.4-1.9]$ & \\
\hline \multicolumn{5}{|l|}{ Adjuvant chemotherapy } \\
\hline No $(n=36)$ & 1 & $p=0.4$ & 1 & $p=0.2$ \\
\hline Yes $(n=10)$ & $1.6[0.5-5.5]$ & & $1.6[0.7-3.8]$ & \\
\hline \multicolumn{5}{|l|}{ GTV coverage } \\
\hline$<95 \%(n=22)$ & 1 & $p=0.1$ & 1 & $p=0.07$ \\
\hline$\geq 95 \%(n=24)$ & $0.45[0.17-1.18]$ & & $0.5[0.2-1.06]$ & \\
\hline \multicolumn{5}{|l|}{ PTV coverage } \\
\hline$<90 \%(n=23)$ & 1 & $p=0.17$ & 1 & $p=0.04$ \\
\hline$\geq 90 \%(n=23)$ & 0.5 [0.19-1.32] & & $0.4[0.2-0.98]$ & \\
\hline
\end{tabular}

${ }^{\mathrm{a}}$ At time of stereotactic ablative radiotherapy; ECOG = Eastern Cooperative Oncology Group

death in locally advanced NSCLC was mainly cancer related, but 3 years after diagnosis, the proportion of death related to cardiovascular disease, other cancer, chronic obstructive pulmonary disease, increases up to $25-40 \%$ [23]. Managing non-cancer related morbidity is still important in this frail population.

Previous studies analyzing SABR reirradiation on the thorax did find similar results as our study, with good survival and acceptable toxicity profile, but included a heterogeneous patient population, including patients of all stages, with locoregional or metastatic relapse, and patients previously treated by CFRT or SABR.

By limiting our scope to stage III NSCLC, our study is one of the first to analyze the outcome of SABR reirradiation in patients with stage III at first diagnosis, with the largest follow-up (47 months) and largest population $(n=46)$ to date. A smaller series that is similar to our current study, reported 17 patients reirradiated for in-field relapse and noted a 1-year OS of $59 \%$ and a 1 -year LC of $86 \%$, but with a $12 \%$ fatal toxicity rate (median follow-up $=18$ months) [10]. Kelly et al described the treatment of 37 patients (initial NSCLC stage: I to IV) with a median follow-up of 15 months: there were $19 \%$ grade 3 alveolitis and $8 \%$ grade 3 esophagitis [24]. Liu et al reported pulmonary toxicities of 72 patients treated with reirradiation (median follow-up $=16$ months), however the prior thoracic irradiation included NSCLC, small-cell lung cancer and esophageal cancer [14]. Other reirradiation series describe a 1-year LC rate ranging between 65 and $77 \%$, none of which analyzed a homogeneous population of stage III NSCLC patients [9, 12, 15, 25]. Prognostic factors for better outcome in the context of locally relapse stage III NSCLC are unknown, In patients with re-irradiated for NSCLC, Kelly et al found that out-of-field recurrences had a better PFS [24], but the patient's initial NSCLC stage ranged from I-IV. In the present study, good candidates for SABR reirradiation in locally relapsed stage III NSCLC patients includes: peripheral tumors, tumor size $<33 \mathrm{~mm}$ (or $13 \mathrm{~mL}$ ), and an 
Table 4 Prognostic factors for progression-free survival (PFS) and overall survival (OS)

\begin{tabular}{|c|c|c|c|c|c|c|}
\hline Variable & 2-yearMFS & Log-Rank & 2-year PFS & Log-Rank & 2-year OS & Log-Rank \\
\hline \multicolumn{7}{|l|}{ Gender } \\
\hline Male $(n=35)$ & $38.6 \%$ & $p=0.4$ & $29.5 \%$ & $p=0.02$ & $49.2 \%$ & $p=0.9$ \\
\hline Female $(n=11)$ & $55.1 \%$ & & $11.3 \%$ & & $45.7 \%$ & \\
\hline \multicolumn{7}{|l|}{ Histology } \\
\hline Squamous $(n=22)$ & $41.3 \%$ & $p=0.5$ & $28.6 \%$ & $p=0.7$ & $31.1 \%$ & $p=0.2$ \\
\hline Non squamous $(n=24)$ & $60.9 \%$ & & $22.5 \%$ & & $66.5 \%$ & \\
\hline \multicolumn{7}{|l|}{ Age } \\
\hline$\geq 66$ years $(n=23)$ & $59.2 \%$ & $p=0.7$ & $22.5 \%$ & $p=0.3$ & $31.3 \%$ & $p=0.02$ \\
\hline$<66$ years $(n=23)$ & $47.6 \%$ & & $27.3 \%$ & & $65.7 \%$ & \\
\hline \multicolumn{7}{|l|}{ Period between irradiations } \\
\hline$>24$ months $(n=20)$ & $50.9 \%$ & $p=0.6$ & $18.2 \%$ & $p=0.5$ & $69.3 \%$ & $p=0.11$ \\
\hline$\leq 24$ months $(n=25)$ & $55.6 \%$ & & $33.4 \%$ & & $37.9 \%$ & \\
\hline \multicolumn{7}{|l|}{ Missing value $(n=1)$} \\
\hline$>12$ months $(n=36)$ & $59.7 \%$ & $p=0.3$ & $27.9 \%$ & $p=0.3$ & $59.5 \%$ & $p=0.07$ \\
\hline$\leq 12$ months $(n=9)$ & $21.4 \%$ & & $18.8 \%$ & & $12.7 \%$ & \\
\hline \multicolumn{7}{|l|}{ Missing value $(n=1)$} \\
\hline \multicolumn{7}{|l|}{ Dose of reirradiation } \\
\hline BED $\leq 130$ Gy $(n=18)$ & $61.1 \%$ & $p=0.15$ & $28.3 \%$ & $p=0.2$ & $47.9 \%$ & $p=0.8$ \\
\hline BED > 130 Gy $(n=28)$ & $44.4 \%$ & & $23 \%$ & & $49.6 \%$ & \\
\hline BEDmin $\leq 50$ Gy $(n=21)$ & $53 \%$ & $p=0.3$ & $21.2 \%$ & $p=0.7$ & $52.9 \%$ & $p=0.4$ \\
\hline BEDmin $>50$ Gy $(n=23)$ & $46.6 \%$ & & $32.2 \%$ & & $42.2 \%$ & \\
\hline \multicolumn{7}{|l|}{ SABR duration } \\
\hline$\geq 6$ days $(n=25)$ & $51.9 \%$ & $p=0.3$ & $21.6 \%$ & $p=0.3$ & $53 \%$ & $p=0.6$ \\
\hline$<6$ days $(n=20)$ & $54 \%$ & & $30.3 \%$ & & $45.2 \%$ & \\
\hline \multicolumn{7}{|l|}{ Number of fractions } \\
\hline$>3(n=30)$ & $50.7 \%$ & $p=0.5$ & $17.5 \%$ & $p=0.4$ & $47.1 \%$ & $p=0.6$ \\
\hline$\leq 3(n=16)$ & $56.6 \%$ & & $40.8 \%$ & & $52.1 \%$ & \\
\hline \multicolumn{7}{|l|}{ Dose per fraction } \\
\hline$>12(n=23)$ & $45.7 \%$ & $p=0.4$ & $26.2 \%$ & $p=0.6$ & $49 \%$ & $p=0.6$ \\
\hline$\leq 12(n=22)$ & $58.8 \%$ & & $24.2 \%$ & & $49.1 \%$ & \\
\hline \multicolumn{7}{|c|}{ Chemotherapy after reirradiation } \\
\hline Yes $(n=10)$ & $50.8 \%$ & $p=0.9$ & $19 \%$ & $p=0.5$ & $38.9 \%$ & $p=0.4$ \\
\hline No $(n=36)$ & $52.6 \%$ & & $27 \%$ & & $51.3 \%$ & \\
\hline \multicolumn{7}{|l|}{ Tumor size } \\
\hline$\geq 33 \mathrm{~mm}(n=21)$ & $42.5 \%$ & $p=0.2$ & $13.7 \%$ & $p=0.2$ & $31.7 \%$ & $p=0.059$ \\
\hline$<33 \mathrm{~mm}(n=22)$ & $58.9 \%$ & & $31 \%$ & & $69.8 \%$ & \\
\hline \multicolumn{7}{|l|}{ Missing value $(n=3)$} \\
\hline \multicolumn{7}{|l|}{ GTV Volume } \\
\hline$\geq 13 \mathrm{~mL}(n=22)$ & $38.4 \%$ & $p=0.12$ & $13.1 \%$ & $p=0.10$ & $27.3 \%$ & $p=0.06$ \\
\hline$<13 \mathrm{~mL}(n=22)$ & $58.9 \%$ & & $31 \%$ & & $70.6 \%$ & \\
\hline \multicolumn{7}{|l|}{ Missing value $(n=2)$} \\
\hline \multicolumn{7}{|l|}{ Performans Status - ECOG ${ }^{a}$} \\
\hline $0(n=27)$ & $57.4 \%$ & $p=0.3$ & $34.2 \%$ & $p=0.6$ & $59.9 \%$ & $p=0.4$ \\
\hline $1(n=11)$ & $60.6 \%$ & & $21.8 \%$ & & $66.3 \%$ & \\
\hline
\end{tabular}

Missing value $(n=8)$ 
Table 4 Prognostic factors for progression-free survival (PFS) and overall survival (OS) (Continued)

\begin{tabular}{|c|c|c|c|c|c|c|}
\hline Variable & 2-yearMFS & Log-Rank & 2-year PFS & Log-Rank & 2-year OS & Log-Rank \\
\hline \multicolumn{7}{|l|}{ Location of relapse } \\
\hline Central $(n=24)$ & $46.7 \%$ & $p=0.9$ & $16.5 \%$ & $p=0.4$ & $43.1 \%$ & $p=0.2$ \\
\hline Peripheral $(n=22)$ & $59 \%$ & & $35.1 \%$ & & $57.5 \%$ & \\
\hline \multicolumn{7}{|c|}{ Primary stage (at first irradiation) } \\
\hline$\| \mathrm{A}(n=21)$ & $59.7 \%$ & $p=0.3$ & $30.6 \%$ & $p=0.3$ & $49.2 \%$ & $p=0.3$ \\
\hline$\| I I \mathrm{~B}(n=25)$ & $44.4 \%$ & & $21.2 \%$ & & $48.6 \%$ & \\
\hline \multicolumn{7}{|l|}{ In-field relapse } \\
\hline Yes $(n=29)$ & $47.4 \%$ & $p=0.4$ & $18.3 \%$ & $p=0.11$ & $42.4 \%$ & $p=0.11$ \\
\hline No $(n=17)$ & $58.8 \%$ & & $37 \%$ & & $61.1 \%$ & \\
\hline \multicolumn{7}{|c|}{ In-field and central tumors } \\
\hline Yes $(n=19)$ & $45.3 \%$ & $p=0.9$ & $14.2 \%$ & $p=4$ & $36.1 \%$ & $p=0.09$ \\
\hline No $(n=27)$ & $57 \%$ & & $33 \%$ & & $60.8 \%$ & \\
\hline \multicolumn{7}{|c|}{ Adjuvant chemotherapy } \\
\hline No $(n=36)$ & $52.6 \%$ & $p=0.8$ & $27 \%$ & $p=0.5$ & $51.3 \%$ & $p=0.4$ \\
\hline Yes $(n=10)$ & $50.8 \%$ & & $19 \%$ & & $38.9 \%$ & \\
\hline \multicolumn{7}{|l|}{ GTV coverage } \\
\hline$<95 \%(n=22)$ & $48.9 \%$ & $p=0.8$ & $19 \%$ & $p=0.6$ & $47.2 \%$ & $p=0.7$ \\
\hline$\geq 95 \%(n=24)$ & $54.4 \%$ & & $33.3 \%$ & & $49.9 \%$ & \\
\hline \multicolumn{7}{|l|}{ PTV coverage } \\
\hline$<90 \%(n=23)$ & $46.6 \%$ & $p=0.9$ & $18.2 \%$ & $p=0.5$ & $44.9 \%$ & $p=0.9$ \\
\hline$\geq 90 \%(n=23)$ & $58.1 \%$ & & $35.6 \%$ & & $52.4 \%$ & \\
\hline
\end{tabular}

${ }^{\mathrm{a}}$ At time of stereotactic ablative radiotherapy; ECOG = Eastern Cooperative Oncology Group

interval between irradiation and in-field relapse $\geq 12$ months. Larger cohorts are required to further delineate the prognostic factors in this population. Toxicity after thoracic reirradiation continues to be a concern. A pooled analysis of 14 studies evaluating toxicity after high-dose reirradiation of NSCLC found mean rates of $7 \%$ for pulmonary toxicity grades $\geq 3$. Grade 5 lethal bleeding was observed in 12 of 408 patients (3\%) [7]. Therefore, it is important to mitigate these toxicities by reducing prescription dose, tumor coverage (to protect proximal bronchial vascular tree (PBV) and lung) or

Table 5 Toxicities

\begin{tabular}{llllll}
\hline Toxicity & Grade 1 & Grade 2 & Grade 3 & Grade 4 & Grade 5 \\
\hline Asthenia & 3 & 3 & 0 & 0 & 0 \\
Alveolitis & 5 & 1 & 0 & 0 & 1 \\
Pneumonitis & 0 & 1 & 0 & 0 & 0 \\
Dysphonia & 0 & 1 & 0 & 0 & 0 \\
Cough & 2 & 0 & 0 & 0 & 0 \\
Hemoptysis & 0 & 0 & 0 & 0 & 1 \\
Esophagitis & 1 & 1 & 0 & 0 & 0 \\
Pain & 2 & 0 & 0 & 0 & 0 \\
Rib fracture & 0 & 1 & 0 & 0 & 0 \\
Breast cancer & 0 & 0 & 1 & 0 & 0 \\
\hline
\end{tabular}

increasing the number fractions. Dose constraints in this setting are difficult to establish when combining a conventional and hypofractionated radiotherapy regimen. Hepel et al identified that $1 \mathrm{cc}$ and $4 \mathrm{cc}$ of PBV should not receive more than a mean dose of $20 \mathrm{~Gy}$ and $15 \mathrm{~Gy}$, respectively [26].

Of note, the patient with fatal hemoptysis in our cohort presented with an elevated mean dose to the PBV (mean dose to 1 and $4 \mathrm{cc}$ were of 53 and $50 \mathrm{~Gy}$, respectively). Other dose constraints used by previous authors during thoracic reirradiation were reviewed by De Bari et al and corresponded with the normal tissue constraint guidelines from RTOG 0813 [12].

Another solution to decrease toxicities could be to increase the number of fractions during SABR, such as 8 fractions instead of 3 or 5 , as already performed by Temming et al [27]. In the context of thoracic reirradiation, Liu et al encourages caution to be taken if patients are PS 2-3, have a forced expiratory volume in $1 \mathrm{~s}$ (FEV1) $<65 \%$, previous PTV spanning bilateral mediastinum or $\mathrm{V} 20 \geq 30 \%$ on the composite plan (SABR + CFRT) [14].

One of the limitations of this present study is its retrospective nature and there was no prospective follow-up of the toxicities. We collected the toxicities reported in the records which can underreport low grades toxicities. 
Table 6 Predictive factors for grade 2 to 5 toxicities

\begin{tabular}{|c|c|c|c|c|c|c|}
\hline Variable & Rate of G2-5 toxicities & Chi Square & Binary logistic regression & $p$-value & Binary logistic regression & $p$-value \\
\hline \multicolumn{7}{|l|}{ Gender } \\
\hline Male $(n=35)$ & $25.7 \%$ & $p=0.2$ & $\mathrm{NI}$ & & $\mathrm{NI}$ & \\
\hline Female $(n=11)$ & $9.1 \%$ & & & & & \\
\hline \multicolumn{7}{|l|}{ Age } \\
\hline$\geq 66$ years $(n=23)$ & $30.4 \%$ & $p=0.15$ & $\mathrm{NI}$ & & $\mathrm{NI}$ & \\
\hline$<66$ years $(n=23)$ & $13 \%$ & & & & & \\
\hline \multicolumn{7}{|c|}{ Period between irradiations } \\
\hline$>24$ months $(n=20)$ & $20 \%$ & $p=0.7$ & $\mathrm{NI}$ & & $\mathrm{NI}$ & \\
\hline$\leq 24$ months $(n=25)$ & $24 \%$ & & & & & \\
\hline \multicolumn{7}{|l|}{ Missing value $(n=1)$} \\
\hline$>12$ months $(n=36)$ & $16.7 \%$ & $p=0.07$ & $\mathrm{NI}$ & & $\mathrm{NI}$ & \\
\hline$\leq 12$ months $(n=9)$ & $44.4 \%$ & & & & & \\
\hline \multicolumn{7}{|l|}{ Missing value $(n=1)$} \\
\hline \multicolumn{7}{|l|}{ Dose of first irradiation } \\
\hline BED < 76 Gy $(n=18)$ & $22.2 \%$ & $p=0.9$ & $\mathrm{NI}$ & & $\mathrm{Nl}$ & \\
\hline BED $\geq 76$ Gy $(n=28)$ & $21.4 \%$ & & & & & \\
\hline \multicolumn{7}{|l|}{ Dose of reirradiation } \\
\hline $\mathrm{BED} \leq 130$ Gy $(n=18)$ & $27.8 \%$ & $p=0.4$ & $\mathrm{NI}$ & & $\mathrm{NI}$ & \\
\hline BED > 130 Gy $(n=28)$ & $17.9 \%$ & & & & & \\
\hline \multicolumn{7}{|l|}{ Tumor size } \\
\hline$\geq 33 \mathrm{~mm}(n=21)$ & $38.1 \%$ & $p=0.02$ & 1 & $p=0.10$ & 1 & $p=0.09$ \\
\hline$<33 \mathrm{~mm}(n=22)$ & $9.1 \%$ & & $\mathrm{OR}=0.22$ & & $\mathrm{OR}=0.21$ & \\
\hline Missing value $(n=3)$ & & & {$[0.04-1.36]$} & & {$[0.04-1.2]$} & \\
\hline
\end{tabular}

GTV Volume

$\geq 13 \mathrm{~mL}(n=22) \quad 36.4 \%$

$<13 \mathrm{~mL}(n=22) \quad 9.1 \%$

Missing value $(n=2)$

SABR duration

$$
\geq 6 \text { days }(n=25) \quad 36 \%
$$$$
<6 \text { days }(n=21) \quad 38.1 \%
$$

Number of fractions

$$
\begin{array}{ll}
>3(n=30) & 26.7 \% \\
\leq 3(n=16) & 12.5 \%
\end{array}
$$

Dose per fraction

$$
\begin{array}{ll}
>12(n=23) & 13 \% \\
\leq 12(n=16) & 30.4 \%
\end{array}
$$

Performans Status - ECOG *

$$
\begin{aligned}
& 0(n=27) \\
& 1(n=11)
\end{aligned}
$$

$9.1 \%$

Missing value $(n=8)$

Location of relapse

$$
\begin{array}{ll}
\text { Central }(n=24) & 37.5 \% \\
\text { Peripheral }(n=22) & 4.5 \%
\end{array}
$$

$p=0.03$

NI

$\mathrm{NI}$

$\mathrm{NI}$

$\mathrm{NI}$

$\mathrm{NI}$

$\mathrm{NI}$ $p=0.07 \quad 1$

$\mathrm{OR}=6.4[1.1-37.7]$ 
Table 6 Predictive factors for grade 2 to 5 toxicities (Continued)

\begin{tabular}{|c|c|c|c|c|c|c|}
\hline Variable & Rate of G2-5 toxicities & Chi Square & Binary logistic regression & $p$-value & Binary logistic regression & $p$-value \\
\hline \multicolumn{7}{|c|}{ In-field relapse and central tumors } \\
\hline No $(n=27)$ & $7.4 \%$ & $p=0.005$ & $\mathrm{NI}$ & & $\mathrm{NI}$ & \\
\hline Yes $(n=19)$ & $42.1 \%$ & & & & & \\
\hline \multicolumn{7}{|c|}{ Primary stage (at first irradiation) } \\
\hline$\| \mathrm{A}(n=21)$ & $28.6 \%$ & $p=0.3$ & $\mathrm{NI}$ & & $\mathrm{NI}$ & \\
\hline IIIB $(n=25)$ & $16 \%$ & & & & & \\
\hline \multicolumn{7}{|l|}{ In-field relapse } \\
\hline Yes $(n=29)$ & $31 \%$ & & 1 & $p=0.3$ & & \\
\hline No $(n=17)$ & $5.9 \%$ & $p=0.04$ & $\mathrm{OR}=0.33[0.03-3.49]$ & & & \\
\hline
\end{tabular}

To minimize this, a phone call was made to all living patients $(n=27)$ to collect missing toxicities. We could not reach 7 patients, which may lead to a recall bias. Due to the retrospective nature of the study (longstanding irradiation or previous irradiation performed in another center) we also could not perform cumulative dosimetry to better appreciate the risk of toxicity. Another limitation of this study is the absence of margin between GTV and CTV: this policy was used in order to decrease the risk of toxicities but this could have led to decreased tumor coverage.

Lastly, although our series includes the largest population of stage III patients reirradiated with SABR, the statistical power may not have been sufficient to detect all putative prognostic factors.

\section{Conclusions}

This study reports long term efficacy and toxicity after SABR reirradiation in 46 patients with locally relapsed stage III NSCLC. Clinical outcome was interesting with a median PFS of 9.6 months and a median OS of 21.8 months. Care must be taken for an in-field relapse and central tumors due to their higher risk of toxicity.

\section{Additional file}

Additional file 1: Table S1. Characteristics of patients with grade 5 toxicities. (DOCX $15 \mathrm{~kb}$ )

\footnotetext{
Abbreviations

3D-CRT: Three dimensional conformal radiation therapy; BED: Biologically effective dose; CFRT: Conventionally fractionated radiation therapy; CR: Complete response; GTV: Gross tumor volume; LC: Local control; LRC: Locoregional control; MFS: Metastasis free survival; NSCLC: Non-small cell lung cancer; OS: Overall survival; PBV: Proximal bronchial vascular tree; PD: Progressive disease; PFS: Progression-free survival; PR: Partial response PTV: Planning tumor volume; RECIST: Response evaluation criteria in solid tumors; SABR: Stereotactic ablative radiation therapy; SD: Stabilized disease; SHR: Subhazard ratio
}

Acknowledgements

Not applicable.

\section{Funding}

This research did not receive any specific grant from funding agencies in the public, commercial, or not-for-profit sectors.

\section{Availability of data and materials}

The datasets used and/or analysed during the current study are available from the corresponding author on reasonable request.

\section{Authors' contributions}

SS collected the data and is a major contributor in the writing of the manuscript. PYB contributed to conception and design of the study. MP contributed to conception and design of the study. CC contributed to collection of data and writing of manuscript. $\mathrm{AON}$ is a major contributor in the writing of the manuscript and the interpretation of data. BP performed the interpretation of CT-scans and conception of the study. DM contributed in collection of data and writing of the manuscript. JG analyzed and interpreted the patients data. AL contributed in collection of data and writing of the manuscript. HG contributed in collection of data and writing of the manuscript. JO contributed to conception and design of the study. JD analyzed and interpreted the patient data and is a major contributor in writing the manuscript. All authors read and approved the final manuscript.

\section{Ethics approval and consent to participate}

Our protocol was approved by the Institutional Review Board of Antoine Lacassagne Cancer Centre (MR001) which approved the ethical aspect of the protocol. The board waived the requirement for informed consents because this study was retrospective.

Consent for publication

Not applicable.

\section{Competing interests}

The authors declare that they have no competing interests.

\section{Publisher's Note}

Springer Nature remains neutral with regard to jurisdictional claims in published maps and institutional affiliations.

\footnotetext{
Author details

${ }^{1}$ Department of Radiation Oncology, Centre Antoine-Lacassagne, 33 av de Valombrose, 06189 Nice, France. ${ }^{2}$ University of Côte d'Azur, Nice, France. ${ }^{3}$ Department of Medical Oncology, Centre Antoine-Lacassagne, 33 av de Valombrose, 06189 Nice, France. ${ }^{4}$ Department of Thoracic Surgery, Hôpital Louis-Pasteur, 30 voie romaine, 06000 Nice, France. ${ }^{5}$ Department of Radiation Oncology, H. Lee Moffitt Cancer Center and Research Institute, 12902 USF Magnolia, Tampa, Florida 33612, USA. ${ }^{6}$ Department of Radiology, Hôpital Louis-Pasteur 2, 30 voie romaine, 06000 Nice, France. ${ }^{7}$ Department of Statistics, Centre Antoine-Lacassagne, 33 av de Valombrose, 06189 Nice, France.
} 
Received: 18 February 2019 Accepted: 28 March 2019 Published online: 03 April 2019

\section{References}

1. Postmus PE, Kerr KM, Oudkerk M, Senan S, Waller DA, Vansteenkiste J, et al. Early and locally advanced non-small-cell lung cancer (NSCLC): ESMO clinical practice guidelines for diagnosis, treatment and follow-up. Ann Oncol. 2017; 28(suppl_4):iv1-iv21 http://www.ncbi.nlm.nih.gov/pubmed/28881918.

2. Garg S, Gielda BT, Kiel K, Turian JV, Fidler MJ, Batus M, et al. Patterns of locoregional failure in stage III non-small cell lung cancer treated with definitive chemoradiation therapy. Pract Radiat Oncol. 2014;4(5):342-8 http://www.ncbi.nlm.nih.gov/pubmed/25194104.

3. Jeremic B, Videtic GM. Chest reirradiation with external beam radiotherapy for locally recurrent non-small-cell lung cancer: a review. Int J Radiat Oncol Biol Phys. 2011;80(4):969-77 http://www.ncbi.nlm.nih.gov/pubmed/21489714.

4. Onishi $H$, Shirato $H$, Nagata $Y$, Hiraoka M, Fujino M, Gomi K, et al. Hypofractionated stereotactic radiotherapy (HypoFXSRT) for stage I nonsmall cell lung cancer: updated results of 257 patients in a Japanese multi institutional study. J Thorac Oncol. 2007;2(7 Suppl 3):S94-100 http://www. ncbi.nlm.nih.gov/pubmed/17603311.

5. Amini A, Yeh N, Gaspar LE, Kavanagh B, Karam SD. Stereotactic body radiation therapy (SBRT) for lung cancer patients previously treated with conventional radiotherapy: a review. Radiat Oncol. 2014;9:210 http://www. ncbi.nlm.nih.gov/pubmed/25239200.

6. Coon D, Gokhale AS, Burton SA, Heron DE, Ozhasoglu C, Christie N. Fractionated stereotactic body radiation therapy in the treatment of primary, recurrent, and metastatic lung tumors: the role of positron emission tomography/computed tomography-based treatment planning. Clin Lung Cancer. 2008;9(4):217-21 http://www.ncbi.n/m.nih.gov/pubmed/ 18650169.

7. De Ruysscher D, Faivre-Finn C, Le Pechoux C, Peeters S, Belderbos J. Highdose re-irradiation following radical radiotherapy for non-small-cell lung cancer. Lancet Oncol. 2014;15(13):e620-4 http://www.ncbi.n/m.nih.gov/ pubmed/25456380.

8. Peulen H, Karlsson K, Lindberg K, Tullgren O, Baumann P, Lax I, et al. Toxicity after reirradiation of pulmonary tumours with stereotactic body radiotherapy. Radiother Oncol. 2011;101(2):260-6 http://www.ncbi.nlm.nih. gov/pubmed/22056534.

9. Reyngold M, Wu AJ, McLane A, Zhang Z, Hsu M, Stein NF, et al. Toxicity and outcomes of thoracic re-irradiation using stereotactic body radiation therapy (SBRT). Radiat Oncol. 2013;8:99 http://www.ncbi.nlm.nih.gov/ pubmed/23617949.

10. Trovo M, Minatel E, Durofil E, Polesel J, Avanzo M, Baresic T, et al. Stereotactic body radiation therapy for re-irradiation of persistent or recurrent non-small cell lung cancer. Int J Radiat Oncol Biol Phys. 2014;88(5): 1114-9 http://www.ncbi.nlm.nih.gov/pubmed/24661664.

11. Patel NR, Lanciano R, Sura K, Yang J, Lamond J, Feng J, et al. Stereotactic body radiotherapy for re-irradiation of lung cancer recurrence with lower biological effective doses. J Radiat Oncol. 2015;4(1):65-70 http://www.ncbi. nlm.nih.gov/pubmed/25774244.

12. De Bari B, Filippi AR, Mazzola R, Bonomo P, Trovo M, Livi L, et al. Available evidence on re-irradiation with stereotactic ablative radiotherapy following high-dose previous thoracic radiotherapy for lung malignancies. Cancer Treat Rev. 2015;41(6):511-8 http://www.ncbi.n/m.nih.gov/pubmed/25913714.

13. Binkley MS, Hiniker SM, Chaudhuri A, Maxim PG, Diehn M, Loo BW Jr, et al. Dosimetric factors and toxicity in highly conformal thoracic Reirradiation. Int J Radiat Oncol Biol Phys. 2016;94(4):808-15 http://www.ncbi.nlm.nih.gov/ pubmed/26831903.

14. Liu H, Zhang X, Vinogradskiy YY, Swisher SG, Komaki R, Chang JY. Predicting radiation pneumonitis after stereotactic ablative radiation therapy in patients previously treated with conventional thoracic radiation therapy. Int J Radiat Oncol Biol Phys. 2012;84(4):1017-23 http://www.ncbi.nlm.nih.gov/ pubmed/22543216.

15. Meijneke TR, Petit SF, Wentzler D, Hoogeman M, Nuyttens JJ. Reirradiation and stereotactic radiotherapy for tumors in the lung: dose summation and toxicity. Radiother Oncol. 2013;107(3):423-7 http://www.ncbi.nlm.nih.gov/ pubmed/23647748.

16. Eisenhauer EA, Therasse P, Bogaerts J, Schwartz LH, Sargent D, Ford R, et al. New response evaluation criteria in solid tumours: revised RECIST guideline (version 1.1). Eur J Cancer. 2009;45(2):228-47 http://www.ncbi.nlm.nih.gov/ pubmed/19097774.
17. Martini N, Bains MS, Burt ME, Zakowski MF, McCormack P, Rusch W, et al. Incidence of local recurrence and second primary tumors in resected stage I lung cancer. J Thorac Cardiovasc Surg. 1995;109(1):120-9 http://www.ncbi. nlm.nih.gov/pubmed/7815787.

18. Timmerman R, McGarry R, Yiannoutsos C, Papiez L, Tudor K, DeLuca J, et al. Excessive toxicity when treating central tumors in a phase II study of stereotactic body radiation therapy for medically inoperable early-stage lung cancer. J Clin Oncol. 2006;24(30):4833-9 http://www.ncbi.nlm.nih.gov/ pubmed/17050868.

19. Whyte RI, Crownover R, Murphy MJ, Martin DP, Rice TW, DeCamp MM Jr, et al. Stereotactic radiosurgery for lung tumors: preliminary report of a phase I trial. Ann Thorac Surg. 2003;75(4):1097-101 http://www.ncbi.nlm.nih.gov/ pubmed/12683544.

20. Benedict SH, Yenice KM, Followill D, Galvin JM, Hinson W, Kavanagh B, et al. Stereotactic body radiation therapy: the report of AAPM task group 101. Med Phys. 2010;37(8):4078-101 http://www.ncbi.nlm.nih.gov/pubmed/20879569.

21. Poudenx M, Bondiau PY, Chamorey E, Venissac N, Otto J, Pourel N, et al. Cisplatin-docetaxel induction plus concurrent 3-D conformal radiotherapy and weekly chemotherapy for locally advanced non-small cell lung cancer patients: a phase II trial. Oncology. 2012;83(6):321-8 http://www.ncbi.nlm. nih.gov/pubmed/22986621.

22. Theelen W, Peulen H, Lalezari F, De Vries J, De Langen J, Aerts J, et al. Randomized phase II study of pembrolizumab after stereotactic body radiotherapy (SBRT) versus pembrolizumab alone in patients with advanced non-small cell lung cancer: the PEMBRO-RT study. J Clin Oncol. 2018;36(15_ suppl):9023 http://ascopubs.org/doi/abs/10.1200/JCO.2018.36.15_suppl.9023.

23. Janssen-Heijnen ML, van Erning FN, De Ruysscher DK, Coebergh JW, Groen HJ. Variation in causes of death in patients with non-small cell lung cancer according to stage and time since diagnosis. Ann Oncol. 2015;26(5):902-7 http://www.ncbi.nlm.nih.gov/pubmed/25672893.

24. Kelly P, Balter PA, Rebueno N, Sharp HJ, Liao Z, Komaki R, et al. Stereotactic body radiation therapy for patients with lung cancer previously treated with thoracic radiation. Int J Radiat Oncol Biol Phys. 2010;78(5):1387-93 http:// www.ncbi.nlm.nih.gov/pubmed/20381271.

25. Trakul N, Harris JP, Le QT, Hara WY, Maxim PG, Loo BW Jr, et al. Stereotactic ablative radiotherapy for reirradiation of locally recurrent lung tumors. J Thorac Oncol. 2012;7(9):1462-5 http://www.ncbi.nlm.nih.gov/pubmed/ 22895143.

26. Hepel JT, Leonard KL, Safran H, Ng T, Taber A, Khurshid H, et al. Stereotactic body radiation therapy boost after concurrent Chemoradiation for locally advanced non-small cell lung Cancer: a phase 1 dose escalation study. Int J Radiat Oncol Biol Phys. 2016;96(5):1021-7 http://www.ncbi.nlm.nih.gov/ pubmed/27745983.

27. Temming S, Kocher M, Stoelben E, Hagmeyer L, Chang DH, Frank K, et al. Risk-adapted robotic stereotactic body radiation therapy for inoperable early-stage non-small-cell lung cancer. Strahlenther Onkol. 2017; http:// www.ncbi.nlm.nih.gov/pubmed/28812120.

Ready to submit your research? Choose BMC and benefit from:

- fast, convenient online submission

- thorough peer review by experienced researchers in your field

- rapid publication on acceptance

- support for research data, including large and complex data types

- gold Open Access which fosters wider collaboration and increased citations

- maximum visibility for your research: over $100 \mathrm{M}$ website views per year

At BMC, research is always in progress.

Learn more biomedcentral.com/submissions 